Currículo sem Fronteiras, v. 20, n. 1, p. 290-312, jan./abr. 2020

\title{
ESCOLA E UNIVERSIDADE: Representações Sociais de estudantes LGBTQIA
}

\author{
Isaias Batista Oliveira Júnior \\ Universidade Estadual do Paraná - UNESPAR
}

\begin{abstract}
Resumo
Esta pesquisa descritiva exploratória tem como objetivo analisar as representações sociais de pessoas Lésbicas, Gays, Bissexuais, Travestis, Transexuais, Transgêneros, Queer, Questionadores, Intersexos, Indecisos, Assexuados e Aliados - LGBTQIA, sobre suas vivências em espaços formais de ensino. O corpus amostral foi composto por 118 participantes de 13 Estados brasileiros que responderam um questionário virtual baseado na Técnica de Associação Livre de Palavras (TALP). As análises dos resultados obtidos foram ancoradas na Teoria das Representações Sociais, seguindo uma perspectiva cognitivo-estrutural e na teoria da análise de conteúdo. Concluímos que a escola foi representada como um espaço de descobertas, medo e exclusão e a universidade como locus de libertação e ao mesmo tempo de preconceito. Portanto, é necessário que essas instituições percebam as várias maneiras de posicionar a sexualidade defendendo o respeito a todos indistintamente.
\end{abstract}

Palavras chave: LGBTQIA. Escola. Universidade. Representações Sociais. Núcleo Central.

\begin{abstract}
This exploratory descriptive research aims at analyzing the social representations of LGBTQIA about their experiences in formal educational spaces. The objective of this exploratory descriptive study is to analyze the social representations of lesbian, gay, bisexual, transsexual, transsexual, transgender, queer, intersex, undecided. The sample corpus was composed of 118 participants from 13 Brazilian states who answered a virtual questionnaire based on the Free Word Association Technique (TALP). The analyzes of the results obtained were anchored in the Theory of Social Representations, following a cognitive-structural perspective and in the content analysis theory. We conclude that the school was represented as a space of discovery, fear and exclusion and the university as the locus of liberation and prejudice. Therefore, it is necessary for these institutions to perceive the various ways of positioning sexuality, defending respect for all indiscriminately.
\end{abstract}

Keywords: LGBTQIA. School. University. Social Representations. Central Core. 


\section{Notas introdutórias}

Não importa o quão diferentes possamos ser em termos de classe, gênero, raça, etnia, orientação sexual, nossa construção identitária, via de regra, se estabelecerá no contexto das relações sociais, culturais e na demarcação de símbolos, de tal forma que é impossível constituirmos uma identidade única, completa, coerente, fixa e imutável. Ao contrário, nos encontramos diante de uma pluralidade de identidades pessoais possíveis que provoca a fragmentação dos sujeitos e evidencia suas diferenças.

No entanto, a primazia de uma identidade, tida como normal, sobre outras, consideradas desviantes, emergirá nas mais distintas instâncias sociais, como na igreja, política, mídia, sociedade, escola, universidade, políticas públicas, etc. Esse processo laborioso se sustenta em "ações punitivas ou recuperadoras, de reclusão ou de regeneração, de ordem jurídica, religiosa ou educativa" (Louro, 2009, p. 88) sobre aqueles que "insistem" em transgredir o processo normalizador de determinada cultura. Nesse artifício de ordenamento, a heteronormatividade ${ }^{1}$ terá papel fundante na forma como o indivíduo será percebido dentro dessas instituições.

Quando esse processo normalizador passa a ser reiterado ou mesmo invisibilizado no currículo ou na organização político-pedagógica nos espaços formais de ensino, aí incluídos a educação básica (Educação Infantil, Ensino Fundamental e Médio) e educação superior, que teoricamente deveriam ser locais de proteção, passam a se configurar num lugar de opressão. Nessas instituições alunos e alunas Lésbicas, Gays, Bissexuais, Travestis, Transexuais, Transgêneros, Queer, Questionadores, Intersexos, Indecisos, Assexuados e Aliados - LGBTQIA - vivem de maneiras distintas, situações delicadas de vulnerabilidade, negação, autoculpabilização e introjeção da LGBTQIAfobia, termo que empregaremos ao fazer referência ao aparato repressor, que atinge essas pessoas e que se manifesta por meio da exploração; desempoderamento; violência sistêmica; imperialismo cultural e; marginalização (Young, 2009).

Esse fenômeno representa problemas reais, pois, além de produzir e (retro)alimentar preconceitos, discriminações, distintas formas de violência e retirada de direitos básicos, acabam por gerar, nas pessoas LGBTQIA, medo, angústia, sofrimento, exclusão e solidão. Esses sentimentos influenciam substancialmente suas relações sociais e tendem a prejudicar seu rendimento escolar, levando-as até a se evadir da escola; não uma evasão por inapetência, mas uma expulsão compulsória por desatendimento a norma (Bento, 2011).

O distanciamento dos espaços formais de ensino poderá impedir seu acesso a oportunidades de emprego ou mesmo a promoção no ambiente de trabalho; obrigando-os à sujeição de subempregos e/ou atividades estigmatizantes, aumentando sua vulnerabilidade às situações de violência e ao uso de drogas e interferindo em sua qualidade de vida e de saúde (Brasil, 2009), pois, mesmo que "[...] a lei tente asseverar e assegurar o direito de todos à educação pública e de qualidade, questões sociais diversas como [...] ser homo/bi/transexual ainda são campeãs no leque de razões que explicam a não permanência de muitos jovens na escola” (Duarte, 2015, p. 34), 
Embora haja uma incipiência acerca dos dados sobre a evasão escolar, causada pela LGBTQIAfobia, a situação de desvalorização e abjeção imposta as pessoas não heterossexualizadas é amplamente disseminada. Prova disso são alguns estudos realizados nos últimos anos acerca desse fenômeno, como "O alcance da LGBTQIAfobia no espaço escolar (nos níveis fundamentais e médios)" (Unesco, 2004); a "Violência contra homossexuais. Todo mundo tem a ver com isso!" (Carrara, 2007); "Revelando Tramas, Descobrindo Segredos: Violência e Convivência nas Escolas" (Abramovay, 2009); "Diversidade Sexual e Homofobia no Brasil: Intolerância e Respeito às Diferenças Sexuais" (Fundação, 2009b), enquete realizada pelo Canal Futura para o Programa Sala de Notícias no qual se discutia a Diversidade Sexual na Escola (Diversidade, 2012), "Ações Discriminatórias no Âmbito Escolar” (Fundação, 2009a); “As representações sociais de universitários de sexualidades LGBT sobre seus processos de escolarização e as implicações em seus projetos de vida” (Duarte, 2015); “O/a diretor/a não viu, a pedagoga não ouviu e a professora não quer falar: discursos docentes sobre diversidade sexual, homofobia e 'Kit Gay’” (Oliveira Júnior, 2013).

Em síntese, esses estudos apontam que muitas das situações de violência relatadas pelos sujeitos LGBTQIA têm sua origem ou aconteceram de fato nos espaços de formação. Surpreendentemente ou não, essas agressões emanam de toda a comunidade escolar, incluindo professores, alunos, equipe pedagógica, direção, familiares, funcionários, pela ausência de estratégias curriculares e pedagógicas de enfrentamento à LGBTAQIAfobia, a ponto de deixar algumas pessoas impossibilitadas psicologicamente de frequentá-los.

Esses dados, por si só, justificam a necessidade de lançarmos novos olhares sobre as vivências de pessoas LGBTQIA no transcorrer do processo de formação, de modo que possamos pensar em estratégias de enfrentamento e promoção da cultura do respeito. Outro fator que sustenta esse imperativo reside no fato de que, ao analisarmos a literatura nacional na área da Educação e da Psicologia, sobre relatos de pessoas LGBTQIA acerca de suas experiências formativas, encontramos um número ínfimo de produções científicas.

Ao realizarmos uma revisão integrativa buscamos informações sobre o problema em questão, constituindo um corpo de conhecimento, dessa forma, empregamos a estratégia PICo (acrônimo de "População, Interesse e Contexto"), para formular a questão de pesquisa na condução do método de revisão, com o intuito de localizar os estudos primários nas bases de dados selecionadas (Takahashi, Saheki, Gardim, 2014). Nesse sentido, o primeiro elemento da estratégia (P) consistiu nas pessoas LGBTQIA, o segundo (I), nas representações sociais e por fim o elemento (Co), no contexto acadêmico. Sendo assim, o escopo de nossa revisão integrativa foi sintetizar resultados obtidos da literatura científica a partir da seguinte questão: quais são as representações sociais de pessoas LGBTQIA sobre sua vivência escolar ou acadêmica?

A busca de estudos primários foi realizada entre maio e julho de 2018, nas bases de dados Google Acadêmico, Periódicos Eletrônicos em Psicologia - PePSIC, Biblioteca Digital Brasileira de Teses e Dissertações - BDBT, SciELO Brasil (Scientific Electronic Library Online) e Catálogo de Teses e Dissertações da CAPES. 
Para a busca de dados utilizamos os seguintes descritores: "representações sociais", "homofobia", "homossexual”, "homossexualidade”, “universidade” e "escola”. Os termos foram inseridos na busca de maneira combinada, utilizando os operadores booleanos (and/e, or/ou e not/não), por exemplo, "representações and homofobia and escola", "representações sociais and homossexualidade or homossexual and escola not enfermagem", caracterizando ao todo seis combinações que foram empregadas em cada base de dados.

Os textos científicos incluídos nessa revisão seguiram critérios específicos, tais como: (1) publicados no período de 2003 a 2018; (2) redigidos em português e no contexto brasileiro; (3) cuja temática apresentasse pertinência com o objetivo da revisão. Não houve delimitação de tipo de texto, por exemplo, artigos, teses, dissertações, anais etc., devido à escassez de publicações científicas sobre a temática. Após essa etapa, buscamos excluir: (1) trabalhos que não faziam parte da área da psicologia e/ou educação; (2) textos com idioma diferente do português e/ou fora do contexto brasileiro; (3) textos cuja centralidade não atendesse ao objetivo da revisão integrativa.

Como resultado encontramos um total de 1235 títulos: Google Acadêmico (913); PePSIC (03); SciELO Brasil (09), BDBT (176), Catálogo de Teses e Dissertações da CAPES (134). Numa primeira análise, após a leitura do título e aplicação dos critérios de inclusão, foram eleitos 12 textos. Num segundo momento, após a leitura dos resumos e aplicação dos critérios de exclusão, 09 estudos não respondiam a pergunta norteadora da revisão integrativa.

A revisão integrativa nos trouxe um número exíguo de 03 trabalhos científicos: "As representações sociais de universitários de sexualidades LGBT sobre seus processos de escolarização e as implicações em seus projetos de vida” (Duarte, 2015), “'Sapatão', 'bicha', 'mulherzinha': as representações sociais da vivência escolar do público LGBT do Recife” (Freitas, Santos, Alves, 2017) e "O debate sobre a homossexualidade mediado por representações sociais: perspectivas homossexuais e heterossexuais” (Scardua, Souza Filho, 2006), os quais faziam referências às representações de pessoas LGBTQIA acerca do ambiente educacional, sejam no contexto universitário ou nas redes de educação básica.

Partindo da limitação de estudos que estabeleçam uma intersecção entre a Educação e a Psicologia, justificamos o desenvolvimento de nosso estudo, pois defendemos a necessidade de ampliar as investigações nessas áreas de forma que possamos compreender e enfrentar determinadas posturas manifestas pelos sistemas de ensino que inferem na realidade social, marcando, regulando e normatizando as pessoas por meio de uma conduta moral hegemônica heteronormativa, que insistentemente se desdobra na violação de direitos e ocasiona os mais distintos prejuízos sociais ao retirar do ato de viver o livre exercício dos modos de ser e sentirse humano.

Dar voz às vivências escolares de pessoas LGBTQIA não se faz apenas necessário, como se torna indispensável. Sendo assim, nos questionamos: como as pessoas LGBTQIA representam suas memórias sobre as ocorrências e acontecimentos vividos dentro da escola e da universidade? Em busca de responder ao problema proposto, objetivamos analisar as representações sociais de pessoas LGBTQIA sobre suas vivências em espaços formais de ensino como a escola e a universidade. 
Tendo em vista tal pressuposto, recorremos à Teoria das Representações Sociais - TRS, a qual aponta que “[...] as representações sociais devem ser vistas como uma 'atmosfera', em relação ao indivíduo ou ao grupo; as representações são, sob certos aspectos, específicas de nossa sociedade” (Moscovici, 2015, p. 53). Esse conhecimento, ao ser compartilhado, acaba por direcionar posturas e condutas que justificam tomadas de posições e a construção de certas identidades, dando resguardo às particularidades de determinados extratos sociais. Dessa forma “a visão de sujeito para essa teoria é contextualizada social e historicamente, pois, ao mesmo tempo em que o sujeito constrói a realidade social, nela é construído de forma ativa [...]” (Ribeiro; Cruz, 2013, p. 615).

Desse modo, a TRS é um campo do conhecimento que busca compreender, por meio das imagens e sentidos partilhados pelos indivíduos, pertencentes a uma determinada realidade, a dinâmica das relações humanas sob o prisma da construção psicossocial. Em outras palavras, as RS (Representações Sociais) evidenciam as motivações dos sujeitos ao construírem e escolherem certas representações do mundo ou de si mesmos.

Esse processo se sustenta em duas etapas essenciais: a ancoragem e a objetivação.

A primeira mantém a memória em movimento e a memória é dirigida para dentro, está sempre colocando e tirando objetos, pessoas e acontecimentos, que ela classifica de acordo com um tipo e rotula com um nome. A segunda, sendo mais ou menos direcionada para fora (para outros), tira daí conceitos e imagens para juntá-los e reproduzi-los no mundo exterior, para fazer as coisas conhecidas a partir do que já é conhecido (Moscovici, 2015, p. 78).

A TRS tem seu desdobramento em pelo menos três abordagens: a primeira, proposta por Jodelet (2015), apresenta um viés antropológico dando sequência à obra original; a segunda, centrada nas condições de produção e circulação das representações sociais, tem como expoente Doise (2015), e a terceira enfatiza a dimensão cognitivo-estrutural, denominada Teoria do Núcleo Central - TNC -, tendo como representante Abric (1998).

Para este estudo recorremos à base teórica proposta por Abric (1998), pois, ao empregarmos seus preceitos, buscamos re/conhecer os mecanismos cognitivos ou afetivos de pessoas LGBTQIA e suas experiências formativas, enquanto indicadores de processos subjetivos, bem como representar os mais distintos mecanismos de defesa que esses sujeitos manifestam, mesmo de maneira inconsistente, a fim de manter seus conflitos dentro de uma margem tolerável. Visto que as representações sociais procuram ilustrar a maneira como um conjunto de conceitos, proposições e explicações históricas, míticas ou de crenças, estabelecidos nas associações originadas em nosso cotidiano, tornam-se senso comum e passam a compor nosso repertório, favorecendo o estabelecimento de parentescos analógicos de uns para com os outros. 


\section{Percurso metodológico}

Adotamos a pesquisa descritiva exploratória já que pretendemos descrever as características de uma determinada população e estabelecer a relações entre variáveis, ou seja, analisar as representações sociais de pessoas LGBTQIA sobre suas vivências em espaços de formação como a escola e a universidade. O projeto de pós-doutoramento em Educação que deu origem a este estudo recebeu financiamento da CAPES - Coordenação de Aperfeiçoamento de Pessoal de Nível Superior - e foi submetido ao credenciamento junto ao Programa de Pós-Graduação em Educação, para análise e mediante aprovação para o Comitê Permanente de Ética em Pesquisa (COPEP) da Universidade Estadual de Maringá, autorizado sob a égide do protocolo $n^{\circ}$ 2.698.275.

Seguido os trâmites legais, disponibilizamos uma Webquest no 'Formulários Google' divulgando-o em redes sociais, como o Facebook e aplicativos de conversas como Messenger e WhatsApp. O questionário virtual foi composto de uma parte explicativa composta pelo objetivo da pesquisa, pela apresentação, pelo público alvo (pessoas que se reconhecessem LGBTQIA), pela solicitação de concordância com o Termo de Consentimento Livre e Esclarecido - TCLE e pela respondência de questões que estruturaram os instrumentos elaborados pelo pesquisador, tais como: questionário sociodemográfico, instrumento baseado na Técnica de Associação Livre de Palavras - TALP, e questionário aberto.

Os indicadores sociodemográficos tiveram como pressuposto delinear o perfil dos participantes, por meio de questões sobre gênero, idade, nível de escolaridade, formação acadêmica, religião, composição e renda familiar etc.

O questionário aberto atendia, principalmente, às finalidades exploratórias, que traziam elementos para o detalhamento de questões e formulações mais precisas relacionadas ao conceito que pretendíamos investigar. Assim, o pesquisador introduziu o tema e o entrevistado teve liberdade para discorrer sobre o assunto sugerido. Sendo assim, este instrumento, composto por uma questão aberta, possibilitou aos participantes relatarem sua trajetória pelo sistema de ensino como pessoas LGBTQIA a partir da seguinte assertiva: faça um relato sobre sua trajetória escolar descrevendo aspectos relacionados à sua homossexualidade, bissexualidade e/ou transexualidade, por exemplo, se algum/a professor/a abordou o assunto, a relação com os colegas de estudos, os eventos escolares, casos de homofobia etc.

O instrumento de investigação, baseado na TALP, consistiu numa abordagem estruturada nas evocações de respostas dadas diante de um estímulo indutor evidenciando grupos semânticos relacionados ao objeto de pesquisa. Nesse sentido, solicitamos aos participantes que preenchessem com cinco palavras o que lhes viesse imediatamente à lembrança com as seguintes frases: "A escola é um local (de)... para pessoas homossexuais, bissexuais e/ou transexuais, travestis e transgêneros" e "A Universidade representa um espaço (de)... para pessoas homossexuais, bissexuais e/ou transexuais, travestis e transgêneros".

Os dados obtidos mediante a TALP foram organizados no programa Excel da Microsoft Office, versão 2013, e posteriormente processados no software EVOC (Ensemble de 
Programmes Permettant I'Analyse dês Êvocations) proposto por Pierre Vergés. O EVOC é composto por dezesseis programas, com funções específicas, sendo que, para este estudo recorremos a cinco deles: LEXIQUE (tem a função de isolar as unidades lexicais do arquivo salvo no Excel em formato CSV - separado por vírgulas); TRIEVOC (organiza as evocações por ordem alfabética após triagem); NETTOIE (permite ao pesquisador excluir acentuação, visto que o programa exige a não acentuação, eliminar possíveis erros de digitação, atribuir mesmo significado a palavras com unidades lexicais similares, dentre outras funções); RANGMOT (lista todas as palavras evocadas por ordem alfabética referenciando a ordem, a média ponderada e a frequência de evocação); RANGFRQ (realiza cálculos estatísticos e obtém matrizes de co-ocorrências que subsidiam a construção do quadro de "quatro casas" ou diagrama de Vergés, em que são enfatizadas as possíveis palavras que compõem o núcleo central das evocações e os elementos intermediários e periféricos).

Para Celso Pereira de Sá (1996a), o EVOC, além de combinar a frequência da emissão de palavras, sentimentos ou imagens com a ordem com que são evocadas, possibilita criar um conjunto de categorias, organizadas ao redor desses elementos, possibilitando a projeção das indicações sobre seu papel organizador das representações, a fim de demonstrar os núcleos de resistência quanto ao assunto investigado.

Para a análise dos diagramas de Vergés nos ancoramos na abordagem estruturalista, que tem como pressuposto que a representação se constitui em duas estruturas elementares: o núcleo-central e o sistema periférico das representações sociais sobre as vivências na educação básica e no Ensino Superior de pessoas LGBTQIA (Abric, 1998). As evocações foram analisadas a partir do diálogo entre as representações sociais obtidas mediante o texto produzido no questionário aberto e as informações oriundas dos quadros de quatro casas.

Para materializar o diálogo entre os dois tratamentos, organizamos categorias com base em critérios semânticos, segundo procedimentos da análise de conteúdo proposta por Bardin (2016). Desse modo, ao fazermos inferências do texto de pessoas LGBTQIA, como estratégia para compreendermos as estruturações discursivas e como ferramenta para analisar suas vivências nos espaços de formação, propomos as seguintes categorias de análise: "A escola como espaço de descobertas que provoca medo e exclusão" e "A universidade como locus de libertação onde impera o preconceito”.

\section{Resultados e discussão}

Responderam à pesquisa 128 pessoas, sendo 10 excluídas da amostra por ainda não terem ingressado no Ensino Superior, totalizando um número de 118 participantes. Desse corpus $71(60,1 \%)$ se autodeclararam do sexo masculino e $47(39,8 \%)$ do sexo feminino. Quanto à orientação sexual, 13 (11\%) se consideraram heterossexuais (vale ressaltar que esses indivíduos se reconhecem transexuais), 17 (14,4\%) bissexuais, 84 (71,1\%) homossexuais e $03(3,3 \%)$ apontaram outras orientações como a pansexualidade (indivíduo que aprecia e é atraído por todos os tipos de gêneros sexuais) e a assexualidade (que não tem ou aparentemente não tem vida sexual). As idades variaram entre 18 e 48 anos, sendo que a 
maioria, representada por 91 participantes $(77,1 \%)$ se concentrou na faixa etária de 18 a 35 anos.

No que se refere à formação acadêmica, a amostra foi composta por 39 pessoas com nível superior incompleto (33\%), 25 com superior completo $(21,1 \%)$ e com pós-graduação em nível latu sensu e strictu sensu (45,7\%). 84 delas realizaram estudos em nível médio ou médio profissionalizante em escolas públicas (71,1\%), 31 em instituições privadas $(26,2 \%)$ e 03 em outras instituições (2,5\%). A atuação profissional se concentrou na área da docência, com 27 pessoas (22,8\%), da psicologia, com 13 (11\%), da enfermagem, com 05 (4,2\%) e outros cursos, com 44 (37,2\%), como: biomedicina, aviação, advocacia, fisioterapia, serviço público etc. Os demais participantes, no total de 29, se encontravam em processo de formação universitária (24,5\%).

Tivemos a participação de sujeitos que residiam em 13 Estados da Federação Brasileira, sendo a maioria do Paraná, no total de 62 (52,5\%), outros 14 de São Paulo (11,8\%), 13 do Rio Grande do Sul (11\%), 08 de Minas Gerais (6,7\%), 07 do Rio de Janeiro (5,9\%) e 14 de demais Estados, como Amazonas, Bahia, Distrito Federal, Mato Grosso do Sul, Paraíba, Pernambuco, Santa Catarina e Sergipe (11,8\%).

O resultado da associação livre de palavras, apontado pelo LEXIQUE e TRIEVOC, diante da frase indutora "A escola é um local (de)... para pessoas homossexuais, bissexuais e/ou transexuais/travestis/transgêneros”, destacou um total de 373 palavras, sendo que destas 156 diferiam entre si. O programa informou que a palavra "preconceito” apareceu com maior número de evocações (21), porém com alta Ordem Média de Evocações (OME), enquanto 85 palavras figuraram uma única vez. A OME empregada foi de 2,4 e a frequência média (f) igual a 10. Por meio desses valores, o RANGFRQ elaborou o Quadro 01, no qual são apresentados os quatro quadrantes com os respectivos grupos semânticos que possivelmente compõem as RS.

Quadro 01: Possíveis elementos centrais e periféricos da representação social de pessoas LGBTQIA sobre a escola.

\begin{tabular}{|c|c|c|c|c|c|}
\hline \multicolumn{3}{|c|}{ Elementos centrais } & \multicolumn{3}{|c|}{ Elementos intermediários $/ 1^{\mathrm{a}}$ periferia } \\
\hline \multicolumn{3}{|c|}{$\begin{array}{l}\text { Alta f e baixa Ordem Média de Evocações } \\
\mathrm{f}>=10 \text { e OME }<2,4\end{array}$} & \multicolumn{3}{|c|}{$\begin{array}{l}\text { Alta f e alta Ordem Média de Evocações } \\
\mathrm{f}>=10 \text { e OME }>=2,4\end{array}$} \\
\hline Grupo semântico de palavras & Freq. & OME & Grupo semântico de palavras & Freq. & OME \\
\hline Descoberta & 11 & 2,091 & Preconceito & 21 & 2,762 \\
\hline Exclusão & 11 & 1,545 & Sofrimento & 10 & 2,500 \\
\hline Medo & 12 & 1,917 & & & \\
\hline \multicolumn{3}{|c|}{ Elementos intermediários $/ 2^{\mathrm{a}}$ periferia } & \multicolumn{3}{|c|}{ Elementos periféricos } \\
\hline \multicolumn{3}{|c|}{$\begin{array}{l}\text { Baixa f e baixa Ordem Média de Evocações } \\
\mathrm{f}<10 \text { e OME }<2,4\end{array}$} & \multicolumn{3}{|c|}{$\begin{array}{l}\text { Baixa f e alta Ordem Média de Evocações } \\
\mathrm{f}<10 \text { e OME }>=2,4\end{array}$} \\
\hline Grupo semântico de palavras & Freq. & OME & Grupo semântico de palavras & Freq. & OME \\
\hline Aprendizado & 8 & 2,125 & Resistência & 6 & 2,500 \\
\hline Bullying & 9 & 2,111 & Solidão & 6 & 3,167 \\
\hline Desrespeito & 5 & 2,000 & Tristeza & 5 & 3,200 \\
\hline
\end{tabular}




\begin{tabular}{|l|l|l|l|l|l|}
\hline Discriminação & 6 & 2,333 \\
Humilhação & 6 & 2,333 & & & \\
Insegurança & 5 & 1,800 & & \\
Opressão & 5 & 1,600 & & \\
Repressão & 6 & 2,167 & & \\
Respeito & 5 & 1,200 & & \\
Tortura & 5 & 2,000 & & \\
Violência & 8 & 2,000 & & \\
\hline
\end{tabular}

Fonte: Elaborado pelo autor (2019).

Ao empregarmos a frase “a Universidade representa um espaço (de)... para pessoas homossexuais, bissexuais e/ou transexuais/travestis/transgêneros” como estímulo indutor, obtivemos um total de 371 palavras, sendo que 161 divergiram entre si. As palavras "libertação" (17) e "preconceito" (17) tiveram maior representatividade, diferentemente de outras 92 que foram evocadas uma única vez. A OME média adotada foi de 2,4 e a frequência média (f), igual a 10. Por meio desses valores, elaboramos, com auxílio do RANGFRQ, o Quadro 02, no qual apresentamos os quatro quadrantes com os respectivos grupos semânticos que possivelmente compõem as RS.

Quadro 02: Possíveis elementos centrais e periféricos da representação social de pessoas LGBTQIA sobre a universidade.

\begin{tabular}{|c|c|c|c|c|c|}
\hline \multicolumn{3}{|c|}{ Elementos centrais } & \multicolumn{3}{|c|}{ Elementos intermediários $/ 1^{\mathrm{a}}$ periferia } \\
\hline \multicolumn{3}{|c|}{$\begin{array}{l}\text { Alta f e baixa Ordem Média de Evocações } \\
\mathrm{f}>=10 \text { e OME }<2,4\end{array}$} & \multicolumn{3}{|c|}{$\begin{array}{l}\text { Alta f e alta Ordem Média de Evocações } \\
\mathrm{f}>=10 \text { e OME }>=2,4\end{array}$} \\
\hline Grupo semântico de palavras & Freq. & OME & Grupo semântico de palavras & Freq. & OME \\
\hline Libertação & 17 & 1,882 & Autoconhecimento & 10 & 2,500 \\
\hline Preconceito & 17 & 2,059 & & & \\
\hline \multicolumn{3}{|c|}{ Elementos intermediários $/ 2^{a}$ periferia } & \multicolumn{3}{|c|}{ Elementos periféricos } \\
\hline \multicolumn{3}{|c|}{$\begin{array}{l}\text { Baixa f e baixa Ordem Média de Evocações } \\
\mathrm{f}<10 \text { e OME }<2,4\end{array}$} & \multicolumn{3}{|c|}{$\begin{array}{l}\text { Baixa f e alta Ordem Média de Evocações } \\
\mathrm{f}<10 \text { e OME }>=2,4\end{array}$} \\
\hline Grupo semântico de palavras & Freq. & OME & Grupo semântico de palavras & Freq. & $\mathrm{OME}$ \\
\hline Aceitação & 6 & 2,167 & Amizade & 8 & 2,875 \\
\hline Acolhimento & 7 & 2,143 & Formação & 7 & 3,143 \\
\hline Afirmação & 8 & 2,125 & Inclusão & 5 & 3,000 \\
\hline Aprendizado & 5 & 2,000 & Independência & 5 & 2,400 \\
\hline Conhecimento & 8 & 2,125 & Pluralidade & 5 & 2,800 \\
\hline Conquistas & 5 & 2,200 & Reconhecimento & 5 & 3,000 \\
\hline Descoberta & 5 & 2,000 & & & \\
\hline Empoderamento & 9 & 2,222 & & & \\
\hline Igualdade & 5 & 1,400 & & & \\
\hline Lutas & 9 & 2,000 & & & \\
\hline Resistência & 6 & 2,000 & & & \\
\hline Respeito & 6 & 1,667 & & & \\
\hline Segurança & 5 & 2,000 & & & \\
\hline Socialização & 5 & 1,600 & & & \\
\hline
\end{tabular}

Fonte: Elaborado pelo autor (2019). 
No diagrama de Vèrges, empregado na elaboração dos Quadros 01 e 02, os elementos que compõem o núcleo central estruturam o primeiro quadrante, por terem maior frequência e baixa Ordem Média de Evocação (OME). O segundo quadrante se estrutura a partir dos elementos que obtiveram alta frequência e maior OME, ou seja, que foram evocados em últimas posições. O terceiro quadrante é composto pelos elementos evocados com baixa frequência e baixa OME. O quarto quadro agrupa os elementos periféricos ou segunda periferia, assim considerados por serem aqueles pouco evocados, mas que possuem alta OME, ou seja, nele estão os elementos menos citados pelos sujeitos, nas primeiras ordens. Assim, a título de interpretação dos quadros, procedemos da seguinte maneira: no quadrante superior esquerdo localizam-se os possíveis elementos que podem organizar o núcleo central da representação; no quadrante superior direito, a primeira periferia dos elementos intermediários; no quadrante inferior esquerdo, os elementos intermediários de segunda periferia; e no quadrante inferior direito, os elementos periféricos das representações.

Nos Quadros 01 e 02, os elementos das ocorrências foram distribuídos em quatro quadrantes, os quais permitem a visualização do núcleo central, os elementos intermediários de $1^{\mathrm{a}}$ e $2^{\mathrm{a}}$ periferia e periféricos de uma representação. Segundo Abric (1994b apud Sá, 1996b, p. 21-22), “[...] as representações são ao mesmo tempo estáveis e móveis, rígidas e flexíveis [...]" e se organizam em torno de um núcleo central, que determina, ao mesmo tempo, sua significação e organização interna, em um sistema periférico que promove a interface entre a realidade concreta e o sistema central (Sá, 1996a, 1996b).

De acordo com a abordagem estrutural, proposta por Abric (1998), o núcleo central possui duas funções principais: "a função geradora, que cria e transforma a significação de outros elementos que constituem a representação; e a função organizadora, que determina a natureza das relações que unem os elementos de uma representação" (Ribeiro; Cruz, 2013, p. 615). Nesse sentido, os elementos do núcleo central e os elementos periféricos são entidades quase tangíveis, que se "[...] entrecruzam e se cristalizam continuamente, através duma palavra, dum gesto, ou duma reunião em nosso cotidiano. Elas impregnam a maioria de nossas relações estabelecidas, os objetos que nós produzimos ou consumimos e as comunicações que estabelecemos [...] (Moscovici, 2015, p. 10)”.

Quando as pessoas emitem julgamentos aparentemente absolutos, já se encontram incutidas, nesses valores, distintas alternativas condicionais tidas como legítimas ou mesmo condicionalmente genéricas ou abertas. É essa hipótese da condicionalidade que propicia um critério analítico para distinguir entre as cognições do núcleo central, consideradas absolutas, e as cognições periféricas, tidas como condicionais, ao mesmo tempo em que permite conferir maior plausibilidade à dinâmica relacional entre os elementos cognitivos dos dois sistemas, como proposta pela TRS (Moscovici, 2015; Sá, 1996a, 1996b).

É válido ressaltar que o sistema periférico complementa, contextualiza e protege o núcleo central, permitindo uma diferenciação das vivências de determinado grupo. Em outras palavras, os dados que subsidiam o sistema periférico fazem a interface entre a realidade concreta e o sistema central. Portanto, ele é indispensável para a manutenção das representações sociais das vivências escolares e acadêmicas de pessoas LGBTQIA. 


\section{A escola como espaço de descobertas que provoca medo e exclusão}

Diante do panorama imediato dos elementos que figuram no possível núcleo central, obtido mediante o emprego da frase indutora "A escola é um local (de)... para pessoas homossexuais, bissexuais e/ou transexuais/travestis/transgêneros”, as palavras “descoberta”, “medo" e “exclusão” foram os principais sentimentos mencionados pelos participantes da pesquisa, podendo ser caracterizados como "[...] elementos unificadores que estabilizam a representação, a base comum, que é coletivamente compartilhada, consensual dentro do grupo e [portanto, mais] resistente às mudanças [...]” (Ribeiro; Cruz, 2013, p. 615). Nesse sentido não seria um erro, a partir das representações do núcleo central, categorizarmos a escola como um espaço de descobertas que provoca medo e exclusão.

A “descoberta” pode ser traduzida numa ação que consistiu no re/conhecimento dos próprios corpos, no modo como as pessoas LGBTQIA perceberam seus sentimentos, definiram, entenderam e passaram a praticar afetos e até mesmo o sexo propriamente dito. Para os participantes da pesquisa, o período de escolarização foi um momento de delimitações da vivência da sexualidade, de questionamentos de modos específicos de vivenciar as relações amorosas:

“Me descobri. Me reencontrei. Me construí” (Participante 101).

"Minha sexualidade se delineou melhor no ensino médio. Foram momentos tensos, de descoberta, crises, encobrimentos" (Participante 106).

“A escola é um lugar de descobertas, do desvelamento da puberdade e do aflorar da sexualidade" (Participante 127).

Embora a vivência da sexualidade ocorra desde o nascimento, a partir da sexuação e da erotização do corpo como parte "estruturante da trajetória pessoal e constituída na complexa combinação de muitos elementos de cunho subjetivo e da relação com o outro”, o período de escolarização, principalmente na educação básica, pode ser considerado um momento de aprendizado, descoberta e invenção da sexualidade (Sayão, 1997, p. 113 -114).

Nesse período é que pode haver o que Foucault (1999, p. 48) denominou de “[...] explosão visível das sexualidades [...]”, pois, mesmo diante de um arsenal de ditos e interditos, as pessoas se (re)constroem por meio de uma rede estratégica de mecanismos entrecruzados ante a proliferação de condutas e prazeres singulares, potencializando a multiplicação das sexualidades “disparatadas”. Nesse sentido, a sexualidade passa a ser manifesta pela atração de ordem afetiva e/ou sexual, que uma pessoa sente por uma ou por várias outras, dentro de um continuum que se manifesta desde a homossexualidade exclusiva à heterossexualidade exclusiva ou permeia-se pelas distintas formas de bissexualidade. 
No entanto, a escola é uma instituição, que nasceu disciplinar e normalizadora, onde a diferença e tudo aquilo que transborda os limites do tolerável incomoda, causa estranhamentos, vigilância e, mesmo que os movimentos em prol da diversidade tenham se fortalecido e forçado sua "entrada” nas práticas escolares, ainda são evidentes as ações de cerceamento e violação das identidades percebidas como transgressoras, principalmente aquelas que afrontam o processo de inculcação da heteronormatividade. Todo esse aparato configura a escola como um lugar de opressão, no qual sujeitos LGBTQIA vivem, de maneiras distintas, situações de violência física, psicológica e emocional. Os efeitos desse processo incidem na vivência negativa da sexualidade, frustração, medo, exclusão, vínculos fragilizados e inconstantes, conforme relataram os participantes da pesquisa:

“Vivia em constate medo" (Participante 02).

"O medo de ser excluído mesmo dentro do espaço acadêmico, faz com que tenhamos que relevar as mais variadas situações” (Participante 18).

"Eu sempre tinha que andar na defensiva porque as agressões eram constantes e o medo de ser pego de surpresa era angustiante" (Participante 37).

"Sempre procurei esconder minha sexualidade na escola, pois, tinha medo de ser espancado" (Participante 46).

“As pessoas que eram homossexuais eram excluídas, motivo de piada e eu não queria passar por isso” (Participante 102).

"Os meninos me chamavam de viadinho e isso me causou susto e medo" (Participante 115).

“Isso era angustiante, eu tinha medo de ir pra aula” (Participante 116).

Para Young (2009), esse temor deve-se, em partes, ao sistema repressor costumeiramente vivenciado no cotidiano escolar, manifesto pela exploração, por desempoderamento, violência sistêmica, imperialismo cultural e marginalização.

A exploração se concentra na desigualdade de condições, fator que permite um determinado grupo, como aquele que se auto reconhece heterossexual, beneficiar-se direta ou indiretamente de outro, como o grupo de pessoas homossexuais (Young, 2009).

"Durante o segundo ano do Ensino Médio um aluno foi perseguido por um professor por ser afeminado, era motivo de chacota constante por parte do mesmo e dos alunos e teve que deixar a escola" (Participante 45).

"Sempre fui alvo de brincadeiras e xingamentos de outros alunos por ser afeminado" (Participante 59). 
Outra face da violência refere-se ao desempoderamento que se caracteriza pela retirada e/ou descumprimento de direitos básicos, como o acesso e a permanência na escola, o uso de espaços comuns, as práticas escolares. Nelas está incluso o currículo, em que subjazem conceitos dogmáticos, especulativos e naturalizantes sobre orientação sexual, seja por meio da linguagem utilizada no cotidiano escolar ou da forma com que os conhecimentos são oferecidos nos livros didáticos e nas disciplinas ou matérias curriculares, assim como na organização sexual dos espaços da escola, conforme relato de participantes da pesquisa:

"Desde o primeiro momento dentro da escola fui hostilizada, agredida, excluída dos espaços” (Participante 70).

"Durante a minha formação no Ensino regular foram poucas as vezes que abordaram o assunto. Lembro-me de que houve indicações de livros sobre o tema e algumas inferências sobre o assunto somente no oitavo ano (antiga oitava série) pela professora de ciências e também pela responsável da sala de leitura. Todavia, tratavam o tema como pejorativo ou em tom de piada, deboche mesmo, o que incentivava a disseminação do preconceito e xingamentos entre os alunos. Foi muito hostilizado por esses xingamentos [...]” (Participante 52).

A violência sistêmica encontra respaldo na proposta de Allport (1954 apud Pinheiro, 2012), fundador da teoria cognitiva do preconceito, em sua obra The Nature of Prejudice. O autor considera a discriminação e o preconceito, manifestos pela LGBTQIAfobia, como subprodutos inevitáveis do modo de pensar e (re)agir das pessoas, sustentado por um ódio irracional nascido na ignorância e nas manobras ego-defensivas de sujeitos com estruturas de personalidade fraca.

As mesmas possuem gradações que vão desde atitudes reconhecidamente horríveis, como matar e/ou espancar, classificadas como ataque físico e/ou extermínio, discriminação social, como as atitudes sutis, como piadas, estereótipos ou imagens negativas, repulsa, isolamento, que às vezes só percebemos se prestarmos atenção, por isso denominadas de “antilocução” e/ou “esquiva”, conforme relatos obtidos em nossa incursão no tema:

"Na sexta série, numa aula de Educação Física [...] um professor me chamou de gay dentro de uma sala de aula com quase 40 alunos, tendo eu apenas 12 anos" (Participante 08).

"Um cara da biblioteca disse que mataria homossexuais (funcionário da escola). [...] Um colega tentou me jogar da ponte uma vez” (Participante 12).

“Além dos xingamentos, levei murro e pedrada dentro da escola mais de uma vez e ninguém foi responsabilizado, mesmo quando eu levava o assunto até à diretoria" (Participante 16).

"Surras na saída da escola, perseguições a pé e humilhações eram constantes, bem como agressões sexuais” (Participante 37). 
“[...] mesmo coordenadores ou diretores das instituições olhavam pra certos meninos e falavam baixo 'boiolinha'” (Participante 44).

"Casos de homofobia não eram levados a sério pela orientação, quando chegava à violência física era tratado como briga entre os dois (as duas) alunos (as), sendo relatado somente o contato físico" (Participante 69).

"Eu era agredido todos os dias e a minha autoestima era inexistente [...] Professores diziam com frequência que ser gay era uma das piores coisas que podia lhe acontecer. Foi dito uma vez, em tom de piada, que a única coisa pior que morrer era virar 'viado"” (Participante 97).

“Fui agredido verbalmente e fisicamente por outros alunos” (Participante 101).

O imperialismo cultural, também evidenciado em nossa pesquisa, ancora-se na adoção de uma matriz identitária, por exemplo a heteronormativa, sendo que as distintas manifestações da sexualidade e tudo o que descumpre seus preceitos passa a ser caracterizado como desviante e, consequentemente, punido com “[...] piadas e gozações, apelidos e gestos para se dirigirem aqueles e àquelas que não se ajustam aos padrões de gênero e sexualidade admitidos na cultura que vivem” (Louro, 2010, p. 28). A ideia de que meninos e meninas devem performar papéis distintos faz com que jovens LGBTQIA sejam percebidos como "estranhos", "errados" e inadequados ao sistema normativo que os seleciona e os segrega (Duarte, 2015, grifos nosso).

"Eu tinha um amigo muito educado na minha sala de aula, ele era diferente dos outros meninos, sempre nos tratava muito bem, não tinha a dita 'masculinidade' que muitos exigem dos homens, ele era tímido, [...]... E por esse jeito dele, falavam que era afeminado" (Participante 71).

“[...] as crianças enxergavam quaisquer características de estereótipos que em seu entendimento indicavam homossexualidade como motivo de chacota e razão para se tirar sarro e diminuir aquela pessoa, ou mesmo se afastar dela" (Participante 17).

Scardua, Souza Filho (2006), Duarte (2015) e Freitas, Santos, Alves (2017), em seus estudos, identificaram a ancoragem do discurso das pessoas LGBTQIA nos aspectos políticos, sociais e morais, em partes, objetivada no preconceito e na luta. O preconceito relatado, o não reconhecimento social, a discriminação, a marginalização, o desrespeito e a proibição, assim como a disseminação de conteúdos agressivos, manifestos em forma de piadas, gozações, exclusão, rotulagem, invisibilidade, apelidos e xingamentos, tais como: "sapatão", "menino", "saboneteira”, "falta de rola” e "cola-velcro" para as meninas e "frango", "mulherzinha”, "bicha” e "viadinho" para os meninos e “mutante”, "ridículo” e 
“feio” para ambos os gêneros, apareceram como vivências do grupo de pessoas LGBTQIA, sendo corroborados pelos dados que encontramos em nossa pesquisa.

As implicações dessas estratégias de subversão resultam num processo de marginalização que pode se desvelar na ausência de acesso às condições básicas de sobrevivência, como educação, emprego, saúde, moradia, dentre outras:

"[...] foi muito complicado porque sofri diversos assédios e algumas vezes eu tive que fazer sexo em troca de dinheiro para poder pagar coisas do meu estudo, comida e moradia. A escola sempre preferiu expulsar do que resolver o caso, ou seja, preferiu transferir meu caso para algo patológico do que encarar o assunto" (Participante 14).

"E antes de conseguir completar a quarta serie, fui vitima de abuso sexual no banheiro masculino e expulsa da escola. E nunca mais voltei a frequentar espaços escolares. Foi um completo desastre na minha vida. Pois acontecia o mesmo em relação a minha família, vivia sendo espancada, fui estuprada por um adulto dentro da minha casa, e depois tentaram me matar. Sai de casa com 15 anos, fui viver nas ruas e me assumi como trans. Descrevo esse período da minha existência, dos 10 aos 24 anos como um terror absoluto" (Participante 70).

No quadrante intermediário de primeira periferia, identificamos elementos em profunda simbiose com o núcleo central das representações, no qual constatamos que o preconceito imposto aos estudantes LGBTQIA lhes causa sofrimento e pode ser traduzido em situações limites manifestas pela prática de bullying, desrespeito, discriminação, humilhação, insegurança, opressão, repressão, desrespeito, tortura e violência, os quais encontram-se referendados pelos elementos de segunda periferia. Todo esse processo tende a acarretar graves danos pessoais, sociais e acadêmicos ao gerar uma hierarquia e excluir do convívio diário aqueles que transgridem identidades fixas, além de desestimular a permanência desses alunos por meio da expulsão compulsória. Observável nos elementos periféricos, esse sistema opressor gera nessas pessoas um sentimento de solidão e tristeza e demanda a construção de processos de resistência voltados ao enfrentamento e de promoção da resiliência. Dessa forma as pessoas LGBTQIA buscam administrar as adversidades, suprir suas necessidades e resolver seus problemas procurando modificar, melhorar ou alterar a resposta diante dos fatores estressores aos quais são submetidas cotidianamente na educação básica.

\section{A universidade como locus de libertação onde impera o preconceito}

Se o percurso de escolarização na educação básica é marcado pela descoberta, pela exclusão e pelo medo, o ingresso na universidade representa, para estudantes LGBTQIA, um momento de mudança, pois "é muito comum que jovens ao entrarem na universidade passem a se reconhecer psicologicamente, ao passo que forjam suas identidades sociais e se agrupam 
de acordo com suas preferências, afinidades e/ou objetivos em comum com os seus pares” (Duarte, 2015, p. 215).

O ingresso no ensino superior é uma transição que traz potenciais repercussões para o desenvolvimento psicológico dos jovens estudantes. Em primeiro lugar, ela representa muitas vezes a primeira tentativa importante de implementar um senso de identidade autônomo [...] que é uma tarefa típica do desenvolvimento na passagem da adolescência para a vida adulta (Teixeira, 2008, p. 186).

Estudo realizado por Duarte (2015), que objetivava discutir e analisar as representações sociais de universitários de sexualidades LGBT sobre os seus processos de escolarização e as implicações deste percurso em seus projetos de vida, destaca o papel do Ensino Superior na formação identitária, no resgate e na re/descoberta enquanto pessoa humana na percepção desses estudantes. Para eles, no Ensino Superior, conseguiram se libertar de alguns valores disseminados na escola, que, de forma angustiante, os impediam de seguir sua trajetória existencial, causando-lhes tristeza e isolamento.

Esse processo de emancipação foi reiterado pelos participantes de nosso estudo ao evocarem o sentimento de "libertação" como elemento figurativo do núcleo central das representações sociais acerca do Ensino Superior.

"Na vida acadêmica falava-se do movimento $\mathrm{LGBTq}+e$ do orgulho que poderíamos ter com isso, sendo assim um espaço de transformação tanto interna como externa para mim (sem medo de demonstrar afeto em público, 'dar pinta', defender o movimento ao mesmo tempo em que defendia quem eu sou)" (Participante, 02).

"Assumi minha homossexualidade quando entrei na faculdade, foi quando realmente me descobri e não era reprimida" (Participante 20).

"Me senti mais livre na faculdade, aonde sempre teve pessoas de todos os tipos e cores, a faculdade pra mim foi muito libertadora" (Participante 29).

"Na Universidade o espaço foi mais aberto e já haviam outras pessoas LGBT+" (Participante 34).

"Na universidade me senti confortável para assumir uma identidade gay, me expressar do jeito que sou, sem precisar me conter quanto ao jeito de falar, andar, gesticular, etc. Na universidade o assunto era debatido pelos alunos e ninguém tinha problemas com isso e havia mais LGBTs do que na escola" (Participante 41).

"Na faculdade tudo mudou. Tive aulas com professores abertamente homossexuais que me deram coragem para me abrir com os colegas e minha família. Fiz amigos pela primeira vez na vida. Passei a frequentar festas e me divertir. Fui eleito para o Centro Acadêmico” (Participante 59). 
“Na universidade meu mundo mudou, me assumi de fato no primeiro semestre e com toda certeza foi a melhor coisa que fiz na minha vida" (Participante 68).

"A Universidade permitiu tornar um ser humano melhor e com maiores chances de ingressar no mercado de trabalho" (Participante 101).

"A faculdade foi um momento de libertação, em que conheci outra realidade, outros grupos e outros modos de pensar" (Participante 116).

Depreendemos que, à medida que pessoas LGBTQIA ingressam no Ensino Superior, sentem-se mais seguras e encorajadas pelos vínculos estabelecidos com seus pares e adquirem autoconfiança pra serem quem realmente são, pois, "além do sentimento de pertencer a um grupo, as amizades possibilitam a partilha de experiências e o apoio em caso de dificuldades” (Teixeira, 2008, p. 194).

Nesse sentido, os vínculos afetivos com os colegas e as relações estabelecidas com os professores contribuem substancialmente para o desenvolvimento de estratégias que auxiliam a lidar com as frustrações e dificuldades. Diferentemente dos demais espaços de escolarização, a universidade é representada como um ambiente acolhedor, motivador e capaz de propiciar estratégias de desenvolvimento cognitivo, afetivo e procedimentais, possibilitando a construção de novos projetos de vida.

Embora, a princípio, a universidade seja considerada um ambiente distinto do escolar, onde a vigilância da instituição pelo estudante é notadamente diminuída, as situações de preconceito são recorrentes e determinam tensões entre os grupos, constituindo elemento central das representações sociais dos participantes dessa pesquisa.

“Na faculdade [...] namorei uma [...] mulher trans que estava começando a transição e ainda existia nas aulas com o nome de registro. Quando começamos a namorar, ela havia parado de frequentar as aulas, quando perguntei o motivo foi porque os colegas para quem ela havia assumido a transexualidade foram bastante desrespeitosos e preconceituosos, [...]. Houve outras situações, com comentários preconceituosos” (Participante 10).

“[...] presenciei muitos colegas e amigos soltarem comentários e agirem de maneiras preconceituosas e não inclusivas [...]. Da mesma forma, quando se pensa a atuação em um campo de estágio, por exemplo, não é levado em consideração que o modo de estar nesses espaços será diferente para um estudante homossexual e/ou transexual" (Participante 17).

“Na universidade [...] os preconceitos são mais sutis/subjetivos” (Participante 39).

Para Costa (2012), esses conflitos podem se manifestar a partir de três perspectivas: a heteronormatividade, cuja qual, o preconceito se dá por meio da sistematização de processos desqualificadores das sexualidades, identidades, comportamentos e comunidades, 
demarcando grupos sociais, desvalorizando-os, como no caso das pessoas LGBTQIA. O heterossexismo - expresso na estrutura da sociedade, nas relações de poder e instituições, como na escola e universidade, nega o acesso a direitos fundamentais de determinadas populações, a exemplo da comunidade LGBTQIA. A comunidade acadêmica, ao incorporar esses modelos, os reforça, por meio de suas atitudes e crenças, constituindo a terceira perspectiva, a qual podemos denominar de "preconceito contra orientações não heterossexuais".

Partindo desses pressupostos, identificamos que as memórias dos participantes deste estudo nem sempre estão atreladas a atos de defesa e enfrentamento, uma vez que suas representações denunciam ataques no espaço acadêmico que reforçavam o preconceito, negavam acolhimento e desrespeitavam as diferenças. A partir desse panorama percebemos que as distintas instituições educacionais, inclusive a universidade, não estão preparadas para promover a cultura do respeito, pois evocam constantemente sustentáculos da heteronormatividade, do heterossexismo e do preconceito. Esse processo se agrava quando essas estratégias subversivas emanam dos próprios professores:

"Na graduação foi à primeira vez que vi professores sendo LGBTfóbicos" (Participante 31).

"Mesmo com toda abertura ainda ouvia piadas de alguns professores e minha orientadora da monografia, por ser religiosa (evangélica) ficava jogando piadas até o dia que avisei a ela que a próxima vez que me sentisse ameaçado iria denunciar ela em todas as instâncias possíveis" (Participante 59).

“Existem sim homofobia e transfobia nas universidades” (Participante 103).

Teixeira (2008) defende que os professores são agentes fundamentais na adaptação à vida acadêmica desses alunos, tanto no plano acadêmico quanto no pessoal. Quando isso não ocorre, o sentimento é de frustração, pois, ao mesmo tempo em que estudantes LGBTQIA têm na universidade a representação de libertação, também a percebem como locus de preconceito.

Ao traçarmos um panorama geral das demais representações que organizam os elementos intermediários e periféricos sobre as vivências universitárias, identificamos que as pessoas LGBTQIA trouxeram como elementos o sentimento de autoconhecimento, ou seja, de re/conhecerem-se como pessoas LGBTQIA. A partir desse ato de descoberta, alegaram ser mais capazes de lutar e resistir contra as adversidades que lhes são impostas, exigir respeito e igualdade de direitos quanto às diferenças. Sendo assim, conceberam a universidade como um espaço de socialização, aceitação, acolhimento, afirmação das múltiplas identidades e valores, aprendizado e conhecimento. Sendo assim a somatória desses fatores é capaz de transformar seus projetos de vidas ao permitir sobrevivência social, empoderamento cultural, material e condutual. 


\section{Considerações Finais}

O arsenal de estratégias que sustentam a LGBTQIAfobia é um fenômeno constantemente reiterado nas distintas instituições sociais, principalmente nos espaços formais de ensino. Sua prática tende a causar nas vítimas solidão, rejeição, resistência de pertença, sujeição, desproteção e insegurança em relação aos outros. Os efeitos desse processo apontam para uma vivência negativa da orientação sexual por meio da internalização da frustração, humilhação, vergonha, medo, dúvida e baixa estima dessas pessoas.

A Teoria das Representações Sociais introduz os estudos a respeito desse fenômeno, contudo a escassa teorização sobre o tema, a partir desse mesmo referencial teórico, é detectável ao recorrermos a uma revisão integrativa. Fato esse que evidencia a necessidade de explorar o fenômeno da LGBTQIAfobia, nos espaços de formação, e suas relações com as representações sociais como forma de delinear estratégias que visem promover a cultura do respeito.

Partindo dessas premissas é que propusemos para este estudo analisar as representações sociais de pessoas LGBTQIA sobre suas vivências em espaços formais de ensino, como na educação básica e na universidade. Alcançamos o objetivo pretendido, pois a interpretação dos dados obtidos a partir dessa investigação nos permitiu conferir significados às diferentes representações sociais que nos auxiliaram na compreensão do sistema de pensamento consensual dos participantes da pesquisa.

Diante dos elementos apresentados no possível núcleo central das representações, bem como pela análise dos discursos dos respondentes da pesquisa, percebemos que a escola, que teoricamente deveria ser um local de promoção dos direitos humanos e não reprodução das diferenças, é vista como um espaço de descobertas que provoca medo e exclusão. A escola, enquanto instituição social, parece não saber ou se esquece de que seus atos, discursos ou mesmo a ausência deles são ferramentas utilizadas no extermínio de direitos, que, em seus múltiplos desdobramentos, pode vir a abortar as possibilidades de conquistas materiais e sociais futuras, destituindo as esperanças e expectativas de vida de estudantes LGBTQIA.

As evocações que comparam o núcleo central aos relatos proferidos pelas pessoas LGBTQIA, ao acionarem suas vivências no espaço universitário, indicaram que a universidade é representada como locus de libertação onde impera o preconceito. Diferentemente da educação básica, é nesse espaço que as pessoas acreditam poderem ser como são, onde os vínculos com os pares são estabelecidos e fundados na aceitação, acolhimento, afirmação das múltiplas identidades, valores, aprendizado e conhecimento. No entanto, semelhantemente à educação básica, não raro universitários LGBTQIA enfrentam situações de violência que se ancoram nos preceitos da heteronormatividade, do heterossexismo e do preconceito contra orientações não heterossexuais. Esse processo emana de toda a comunidade escolar e universitária, onde atitudes, falas, gestos ou mesmo ocultamento resultam na legitimação desses comportamentos por parte da sociedade. As atitudes de discriminação e exclusão nesses espaços, vinculadas ao tratamento diferenciado com esses alunos, podem contribuir para que os mesmos incorporem esses preconceitos e pensem a si mesmos como "realmente diferentes". 
Diante desse panorama é evidente que a LGBTQIAfobia permeia todo o processo de formação de pessoas não heterossexualizadas, sendo agravada na educação básica, quando os corpos sofrem maior vigilância, e amenizada no Ensino Superior onde os sujeitos passam a se reconhecer como são e defender seus direitos de sê-lo. Sendo assim, enquanto estudiosos da temática, precisamos fornecer subsídios para que a comunidade escolar e universitária coloque seus sentidos a postos e perceba as distintas maneiras de posicionar a sexualidade como algo positivo, defendendo o respeito a todos indistintamente.

Portanto, propomos algumas possíveis estratégias de enfrentamento à LGBTQIAfobia, como a revisão dos currículos escolares e acadêmicos, no que se refere à inserção da temática sobre a diversidade sexual e os impactos da violência contra pessoa LGBTQIA, a capacitação de professores para tratar dessa temática, o desenvolvimento e a oferta de materiais didáticos que subsidiem a atuação em sala de aula nesse sentido; a discussão da diversidade sexual em sala de aula e em eventos de extensão; o incentivo à pesquisa na área; a inclusão de conteúdos sobre gênero e diversidade sexual no projeto escolar e na grade curricular dos cursos de formação inicial e continuada; o debate nos espaços formais de ensino com as demais esferas sociais, como a saúde e assistência social, sobre ações e propostas de enfrentamento à LGBTQIAfobia; a criação de políticas assistenciais e de saúde para alunos LGBTQIA em situação de vulnerabilidade; o atendimento psicossocial a alunos expostos às distintas violências por orientação sexual; dentre outras.

À guisa da conclusão depreendemos que a metodologia desenvolvida e os resultados obtidos por meio desta pesquisa nos ofereceram informações importantes a respeito do tema, porém, o que apresentamos é apenas um fragmento dentro de um universo de possibilidades de novos olhares. Defendemos que a TRS pode contribuir substancialmente para investigações semelhantes na área da Psicologia e da Educação e, nesse sentido, apontamos a necessidade de novas pesquisas que incluam as vivências escolares de pessoas LGBTQIA, de modo a evidenciar a intransigência social em relação à homossexualidade masculina (ideia implícita à noção de homofobia), a qual não é da mesma ordem do desrespeito que atinge lésbicas (oprimidas por uma lesbofobia que, além de homofóbica, é machista e sexista), nem do repúdio que sistematicamente atinge pessoas travestis, transgêneros e transexuais, cujas existências ferem de morte os binarismos macho-fêmea, homem-mulher, tornando-as vítimas preferenciais do terrorismo de gênero.

Finalizamos as discussões aqui apresentadas reafirmando a necessidade de dar voz às vivências escolares de pessoas LGBTQIA, pois, como afirmou o Participante 84 desta pesquisa: "[...] com toda a certeza é um assunto que precisa ser debatido com a maior seriedade e comprometimento possível, já que vencer àqueles que nos veem com maus olhos é uma tarefa bastante árdua", pois é ouvindo-as que podemos pensar na ampliação das estratégias de combate e enfrentamento às distintas táticas subversivas a que são submetidas na escola. 


\section{Notas}

1. Estratégia difundida corriqueiramente em nossa sociedade e reiterada pelos sistemas de ensino. Ela se desenvolve cotidianamente nas práticas a serviço da consolidação do imperativo heterossexual em detrimento das outras formas de orientação sexual e materialização de normas regulatórias, em que uma das formas de manifestação da sexualidade (heterossexualidade) recebe um valor positivo e privilegiado, enquanto as outras, um cunho negativo (homossexualidade, bissexualidade etc.).

\section{Referências}

ABRAMOVAY, Miriam (Coord.). Revelando tramas, descobrindo segredos: violência e convivência nas escolas. Brasília: Rede de Informação Tecnológica Latino-Americana - RITLA, Secretaria de Estado de Educação do Distrito Federal - SEEDF, 2009.

ABRIC, Jean Claude. A abordagem estrutural das representações sociais. In: MOREIRA, Antônia Silva Paredes, OLIVEIRA, Denize Cristina de (Orgs.). Estudos interdisciplinares de representação social. Goiânia: AB, 1998. p. 27-38.

BARDIN, Laurence. Análise de Conteúdo. Tradução: Luís Antero Reto e Augusto Pinheiro. São Paulo: Edições 70, 2016.

BENTO, Berenice. Na escola se aprende que a diferença faz a diferença. Estudos Feministas, Florianópolis, mai./ago. 2011, p. 549-559.

BRASIL. Gênero e diversidade na escola: formação de professoras/es em Gênero, Orientação Sexual e Relações Étnico-Raciais. Livro de conteúdo. v.1, versão 2009. Rio de Janeiro: CEPESC; Brasília: SPM, 2009.

CARRARA, Sérgio. Política, direitos, violência e homossexualidade: pesquisa 5 a Parada da Diversidade realizada em Pernambuco no ano de 2006. Rio de Janeiro: CEPESC, 2007.

COSTA, Ângelo Brandelli. Preconceito contra orientações não-heterossexuais no Brasil: critérios para avaliação. 116 fls. Dissertação (Mestrado em Psicologia Social e Institucional). Instituto de Psicologia, Universidade Federal do Rio Grande do Sul, Porto Alegre, 2012.

DIVERSIDADE sexual na escola. Programa Sala de Notícias. Produção de Paula Fontes, Sara Oliveira e Jaqueline Souza. Rio de Janeiro: Canal Futura, 2012b, parte 03.

DOISE, Willem. Psicologia social e mudança social. In: JESUÍNO, Jorge Correia. MENDES, Felismina R.P. LOPES, Manuel José (Orgs.). As Representações Sociais nas sociedades em mudança. Petrópolis, RJ: Vozes, 2015, p. 184-207.

DUARTE, Francisco Ednardo Barroso. As representações sociais de universitários de sexualidades LGBT sobre seus processos de escolarização e as implicações em seus projetos de vida. $307 \mathrm{fls}$. Tese (Doutorado em Educação). Instituto de Ciências da Educação, Universidade Federal do Pará, Belém, 2015.

FOUCAULT, Michel. História da sexualidade 1: a vontade de saber. Tradução de Maria Thereza da Costa Albuquerque e J. A. Guilhon Albuquerque. 13. ed. Rio de Janeiro: Graal, 1999.

FREITAS, Ariane Rafaela de; SANTOS, Francineide Marques da Conceição; ALVES, Isabella Nara Costa. "Sapatão", "bicha", "mulherzinha": as representações sociais da vivência escolar do público LGBT do Recife. Anais... IV CONEDU - Congresso Nacional de Educação, V. 1, 2017, p. 1-12. 
FUNDAÇÃO Instituto de Pesquisas Econômicas. Projeto de estudo sobre ações discriminatórias no âmbito escolar, organizadas de acordo com áreas temáticas, a saber, étnico-racial, gênero, geracional, territorial, necessidades especiais, socioeconômica e orientação sexual. São Paulo, 2009a. Disponível em: <http://portal.mec.gov.br/dmdocuments/relatoriofinal.pdf>. Acesso em: 03 jan. 2013.

FUNDAÇÃO Perseu Abramo. Diversidade sexual e homofobia no Brasil intolerância e respeito às diferenças sexuais. São Paulo, 2009b. Disponível em: $<$ http://novo.fpabramo.org.br/sites/default/files/PESQUISA_COMPLETA_Apres-LGBT-Totalmai09.pdf $>$. Acesso em: 04 jan. 2013.

JODELET, Denise. O encontro dos saberes. In: JESUÍNO, Jorge Correia. MENDES, Felismina R.P. LOPES, Manuel José (Orgs.). As Representações Sociais nas sociedades em mudança. Petrópolis, RJ: Vozes, 2015, p. 59-79.

LOURO, Guacira Lopes. Heteronormatividade e Homofobia. In: JUNQUEIRA, Rogério Diniz (Org.). Diversidade Sexual na Educação: problematizações sobre a homofobia nas escolas. Ministério da Educação: SECADI/MEC. Brasília, 2009, p. 85-95.

LOURO, Guacira Lopes. Pedagogias da sexualidade. In: LOURO, Guacira Lopes (Org.). SILVA, Tomaz Tadeu da (Trad.). O corpo educado. 3. ed. Belo Horizonte: Autêntica, 2010, p. 07-35.

MOSCOVICI, Serge. Representações sociais: investigações em psicologia social. Tradução Pedrinho A. Guareschi, 11. ed. Petropólis, RJ: Vozes, 2015.

OLIVEIRA JÚNIOR, Isaias Batista de. O/a diretor/a não viu, a pedagoga não ouviu e a professora não quer falar: discursos docentes sobre diversidade sexual, homofobia e "Kit Gay". 2013. $260 \mathrm{f}$. Dissertação (Mestrado em Educação) - Universidade Estadual de Maringá. Maringá, 2013.

PINHEIRO, Lívia. O que é homofobia. Edição de Daniel Rodrigues. Narração de Vanessa Meriqui. 2012.

RIBEIRO, Fernanda Siqueira; CRUZ, Fatima Maria Leite. Representações sociais de família por crianças na cidade de Recife. Psicologia \& Sociedade, Belo Horizonte, v. 25, n. 3, p. 612-622, 2013.

SÁ, Celso Pereira de. Núcleo central das representações sociais. Petrópolis, RJ: Vozes: 1996a.

SÁ, Celso Pereira de. Representações Sociais: Teoria e Pesquisa do Núcleo Central. Temas em Psicologia. n. 3, p. 19-33, 1996b,

SAYÃO, Yara. Orientação sexual na escola: os territórios possíveis e necessários. In: AQUINO, Júlio Groppa. Sexualidade na escola: alternativas teóricas e práticas. São Paulo: Summus, 1997, p. 107118.

SCARDUA, Anderson. SOUZA FILHO, Edson Alves de. O debate sobre a homossexualidade mediado por representações sociais: perspectivas homossexuais e heterossexuais. Psicol. Reflex. Crit. [online]. 2006, vol.19, n.3, p.482-490.

TAKAHASHI, Juliana. SAHEKI, Yuka. GARDIM, Sonia. O que é PICO e PICo? USP: 2014.

TEIXEIRA, Marco Antônio Pereira; DIAS, Ana Cristina Garcia; WOTTRICH, Shana Hastenpflug; OLIVEIRA, Adriano Machado. Adaptação à universidade em jovens calouros. In: Revista Semestral da Associação Brasileira de Psicologia Escolar e Educacional. v. 12, n. 01, janeiro-junho. p. 185-202. ABRAPEE: São Paulo, 2008.

UNESCO. O perfil dos professores brasileiros: o que fazem, o que pensam, o que almejam. Pesquisa Nacional UNESCO. São Paulo: Moderna, 2004 
YOUNG, Iris Marion. Five Faces of Oppression. In: HENDERSON, George, WATERSTONE, Marvin (Ed.). Geographic Thought: a praxis perspective. New York: Routledge. 2009, p. 55-71.

\section{Correspondência}

Isaias Batista Oliveira Júnior: É Professor Colaborador na Universidade Estadual do Paraná - UNESPAR. E-mail: jr_oliveira1979@hotmail.com

Texto publicado em Currículo sem Fronteiras com autorização do autor 